Bull. Mater. Sci., Vol. 36, No. 4, August 2013, pp. 719-727. (C) Indian Academy of Sciences.

\title{
Effect of plating time on growth of nanocrystalline Ni-P from sulphate/glycine bath by electroless deposition method
}

\author{
N LATHA, V RAJ ${ }^{\dagger, *}$ and M SELVAM ${ }^{\dagger \dagger}$ \\ Department of Chemistry, Kandaswamy Kandar's College, Paramathy-Velur 638 182, India \\ ${ }^{\dagger}$ Advanced Materials Research Laboratory, Department of Chemistry, Periyar University, Salem 636 011, India \\ ${ }^{\dagger}$ Industrial Metal Finishing Division, Central Electrochemical Research Institute, Karaikudi 630 006, India
}

MS received 25 November 2011; revised 25 April 2012

\begin{abstract}
Nanocrystalline nickel phosphorus (NC-Ni-P) deposits from sulphate/glycine bath using a simple electroless deposition process is demonstrated. In the present investigation, nanoporous alumina films are formed on the aluminium surface by anodization process followed by deposition of nickel onto the pores by electroless plating method. Anodic aluminium oxide surface was first sensitized and activated by using palladium chloride solution before immersing into the electroless nickel bath. Electroless nickel plating was carried out from the optimized bath by changing the deposition time from 20 to $1800 \mathrm{~s}$ at a constant temperature of $80{ }^{\circ} \mathrm{C}$ and a pH of 4.0. Surface morphology, elemental composition, structure and reflectance of the deposits have been analysed by using scanning electron microscopy, atomic force microscopy, energy dispersive X-ray analysis, X-ray diffractometry and UV-visible spectroscopic studies, respectively. Electroless nickel deposits formed at an early stage produces dense uniform nanocrystals containing higher percentage of atomic phosphorus with cubic Ni (111) structure. As the deposition time increased, nanocrystalline sharp peak became amorphous and dimension of the crystal size varied from 54 to $72 \mathrm{~nm}$.
\end{abstract}

Keywords. NC-Ni-P; electroless deposition; aluminium; anodization.

\section{Introduction}

Nanocrystalline nickel phosphorus (NC-Ni-P) deposition has been an emerging area for researchers and scientists due to its applications in chemical, aerospace, automobile and textile industries (Mallory and Hajdu 1990; Parker 1992), since the discovery of electroless nickel-phosphorus (ENP) coatings (Brenner and Riddell 1946) and nanoporous anodic alumina films (Masuda and Fukuda 1995). The high insulation ability of anodic oxide film formed on aluminium substrate is mainly of porous $\mathrm{Al}_{2} \mathrm{O}_{3}$ in the as formed condition. Metallization of these nanopores of AAO films will generate nanowires or nanorods.

Nanostructured metals have been prepared by various methods such as PVD, CVD, electrodeposition, electroless deposition, ball milling, mechanical alloying, severe plastic deformation, sol-gel techniques, etc (Chow and Ovid'ko 2000; Meyer et al 2006). Among these methods, electroless deposition is one of the most attractive methods for the formation of nanocrystalline structures (Shacham-Diamad and Sverdlov 2000). Ni-P can be prepared by electroless deposition (Sevugan et al 1993; Keong et al 2002) from solutions

\footnotetext{
*Author for correspondence (alaguraj2@ rediffmail.com)
}

containing metal salt and sodium hypophosphite as a reducing agent.

In ENP coatings, variation in phosphorus content influences crystal structure and surface morphology of the deposit. ENP coatings containing 1.9-3.7 at.\% $\mathrm{P}$ are crystalline/ microcrystalline (Martyak and Drake 2000) and phosphorous content higher than 17.4 at.\% are amorphous in nature (Kumar and Nair 1994). Alloys with intermediate compositions have semi-amorphous or amorphous structures (Apachitei et al 1998) and deposit with 20.3 at.\% phosphorus content consists of nanocrystalline and not amorphous (Goldenstein et al 1957; Tyagi et al 1985; Hur et al 1990) structure. According to the literature, increase in phosphorus content decreases grain size of the as-deposited electroless Ni-P. Properties and growth of the coating are significantly affected by bath parameters such as electrolyte concentration, $\mathrm{pH}$, temperature, deposition time and nature of substrates.

A complexing agent is required for the deposition of Ni-P; sodium acetate (Fundo and Abrantes 2007), citrate (Li et al 2005), lactate (Baskaran et al 2006) and glycine with acetate (Huang and Cui 2007) were studied as the complexing agents. The sulphate/glycine/sodium hypophosphite electrolyte can produce NC-Ni-P deposit of high structural quality. The present work deals with the effect of plating time on the morphology, crystalline structure and composition of NC$\mathrm{Ni}-\mathrm{P}$ coatings formed from the sulphate/glycine/sodium hypophosphite electrolyte by electroless plating method. 


\section{Experimental}

AA 1100 aluminium specimens with dimensions $7 \times 1 \times$ $0.1 \mathrm{~cm}$ were degreased in acetone, etched in a solution containing $50 \mathrm{~g} / 1$ sodium hydroxide for $2 \mathrm{~min}$ at room temperature, rinsed well and immersed for $1 \mathrm{~min}$ in $20 \%(\mathrm{v} / \mathrm{v})$ nitric

\section{Anodized Aluminium}
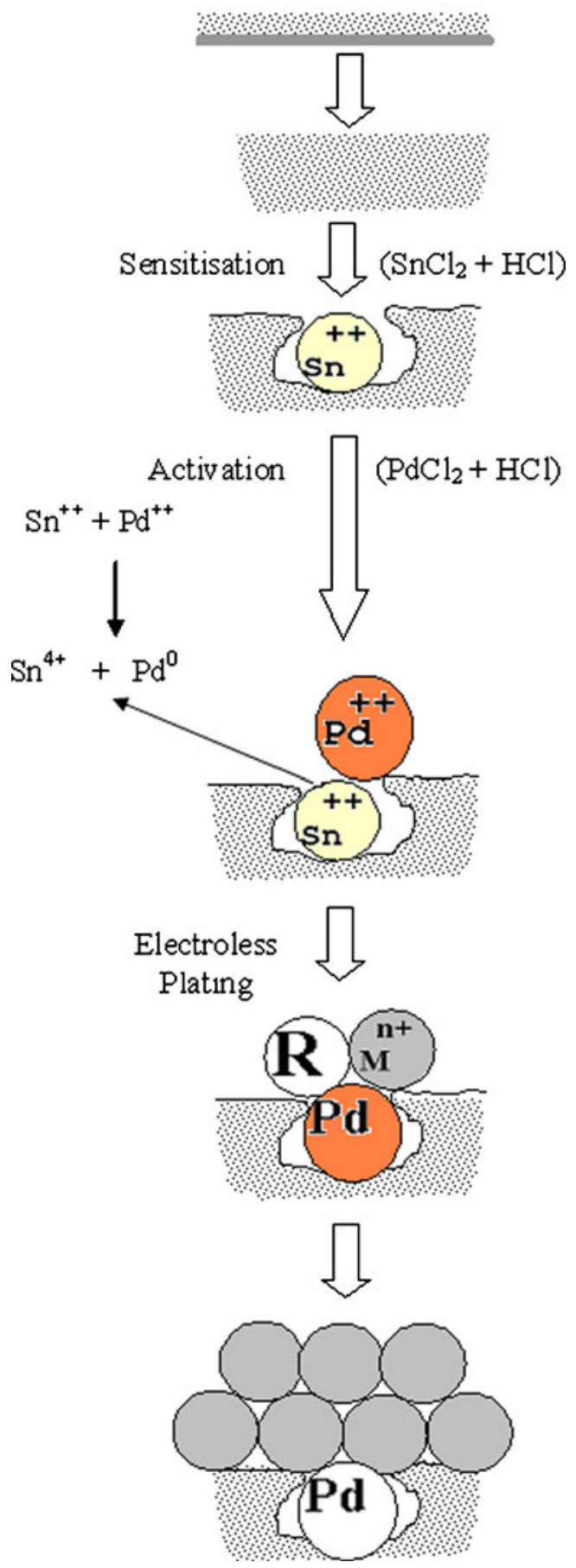

Figure 1. Schematic outline of electroless Ni-P plating on aluminium. acid at room temperature. All the solutions were prepared using double distilled water. The pretreated aluminium specimen was anodized in $10 \%$ sulphuric acid at a constant current density of $0.8 \mathrm{~A} / \mathrm{dm}^{2}$ at $20 \pm 1{ }^{\circ} \mathrm{C}$ (with cooling and agitation) for $30 \mathrm{~min}$ to obtain porous anodic aluminium oxide film. Then the specimen was sensitized by immersing in a solution containing $10 \mathrm{~g} / 1 \mathrm{SnCl}_{2}$ and $40 \mathrm{ml} / 1 \mathrm{HCl}$ for $2 \mathrm{~min}$ at $30{ }^{\circ} \mathrm{C}$ and activated by dipping in a solution containing $1 \mathrm{~g} / 1 \mathrm{PdCl}_{2}$ and $10 \mathrm{ml} / 1 \mathrm{HCl}$ for $30 \mathrm{~s}$ at $30{ }^{\circ} \mathrm{C}$. After each pretreatment step, the substrate was rinsed in deionized water. The entire procedure for the formation of $\mathrm{Ni}-\mathrm{P}$ nanocrystals on aluminium surface is schematically represented in figure 1.

Electroless nickel (EN) plating was carried out immediately after activation. The optimized electroless Ni-P plating bath consisted of nickel sulphate $(42 \mathrm{~g} / \mathrm{l})$, sodium hypophosphite $(21 \mathrm{~g} / \mathrm{l})$, glycine $(11 \mathrm{~g} / \mathrm{l})$ as the nickel ion provider, metal-reducing agent and complexing agent, respectively. Temperature of the bath was maintained at $80{ }^{\circ} \mathrm{C}$. The $\mathrm{pH}$ of the plating bath was fixed at 4.0 and adjusted with $20 \%$ $\mathrm{H}_{2} \mathrm{SO}_{4}$ solution. EN bath is highly sensitive to impurities and hence prior to its use, the solution was filtered through Whatman No. 40 filter paper.

Morphological characterization of the coated specimens was carried out by scanning electron microscopy (SEM, JEOL-Japan-JSM-840A), atomic force microscopy (AFM) (Digital Instruments CP-II Veeco Company, USA) and the elemental composition of the deposits were analysed by energy dispersive X-ray spectroscopy (EDAX, Oxford link ISIS 300). The structure and grain size of the Ni-P deposits were determined using a Philips X'pert X-ray diffractometer (XRD) with $\mathrm{CuK} \alpha$ radiation $(\lambda=0.15418 \mathrm{~nm})$. UV-visible reflectance spectra of the electroless Ni-P deposit was recorded using Hitachi U-3400 spectrophotometer.

\section{Results and discussion}

\subsection{SEM analysis}

The surface morphology, crystalline growth and structure of NC-Ni-P deposits formed on anodized aluminium by electroless nickel plating were investigated by SEM analysis. SEM images of electroless Ni-P deposits on anodic aluminium oxide (AAO) film obtained at various deposition times from 20 to $1800 \mathrm{~s}$ are presented in figure $2(\mathrm{a}-\mathrm{k})$. The $\mathrm{Ni}-\mathrm{P}$ coatings formed at 20 and $30 \mathrm{~s}$ have nodular morphology as shown in figure $2(a, b)$. It indicates that, the honeycomb porous alumina layer of the film is completely covered by small crystals of Ni-P. The tiny Ni-P crystals formation on the AAO film is clearly observed at the deposition time of $50 \mathrm{~s}$ as shown in figure 2(c). Deposition of Ni-P coatings formed at 90 and $120 \mathrm{~s}$ under the same conditions, produced clusters of large number of homogeneous nanocrystalline black Ni-P. At this stage, nanocrystals are cojoined and coalesced to nucleation growth, which can be seen clearly in figure $2(\mathrm{~d}, \mathrm{e})$. By further increase in the deposition time from 180 to $1800 \mathrm{~s}$, it can be observed that, the dimension 
of the crystal size increases and the number of nanocrystals decreases as seen in figure $2(\mathrm{f}-\mathrm{k})$ (Wang et al 2003). Dense coverage of Ni-P granular deposits is seen up to $300 \mathrm{~s}$ with crystals size in nanometer range and hence the $\mathrm{Ni}-\mathrm{P}$ coatings are nanocrystalline in nature. When the deposition time is increased to $1800 \mathrm{~s}$, spherical nodules are clearly observed in the coatings. It is supported by the earlier report ( $\mathrm{Lu}$ and Zangari 2002). The deposit is compact and smooth throughout the coated surface in all deposition times without any cracks or defects. Variation in surface morphology of these coatings suggests a definite dependence on their phosphorus content (Zhao et al 2007). From the comparison of the surface morphologies, it can be found that, by increasing deposition time, moderate change in atomic percent of phosphorus in a parabolic fashion with increasing grain size of $\mathrm{Ni}-\mathrm{P}$ alloy coatings is observed. It can also be found that, the grain size of Ni-P alloy coatings with phosphorus content above 20 at. \% P indicates nanocrystalline structures. Energy dispersive spectroscopic analysis confirms phosphorus content in the electroless $\mathrm{Ni}-\mathrm{P}$ coatings.

\subsection{EDAX analysis}

EDAX analysis was carried out to determine the composition of elements present in the coated specimen. Figure 3(a, b) shows EDAX spectra of the electroless $\mathrm{Ni}-\mathrm{P}$ coatings on anodized aluminium at 30 and $1800 \mathrm{~s}$, respectively. EN deposition process can be categorized into two steps. The first step is related to the formation of a thin film on the porous aluminium substrate and the second step is bulk coating. The mechanism of the first step consists of nucleation, growth and coalescence of crystals (Liu and Gao 2006).

In the first step of electroless nickel deposit at $30 \mathrm{~s}$ (figure 3(a)), the spectrum shows $\mathrm{P}, \mathrm{Ni}$ and $\mathrm{S}$ peaks. The $P$ peak in the EDAX spectrum reveals that phosphorus is co-precipitated with Ni during electroless nickel deposition. Presence of $S$ peak may probably come from sulphuric acid anodizing bath (Goueffon et al 2009). Figure 3(b) is the EDAX spectrum of bulk deposit produced in $1800 \mathrm{~s}$. The coating consists of only $\mathrm{Ni}$ and $\mathrm{P}$ elements and not sulphur element. EDAX spectrum clearly reveals that, increasing
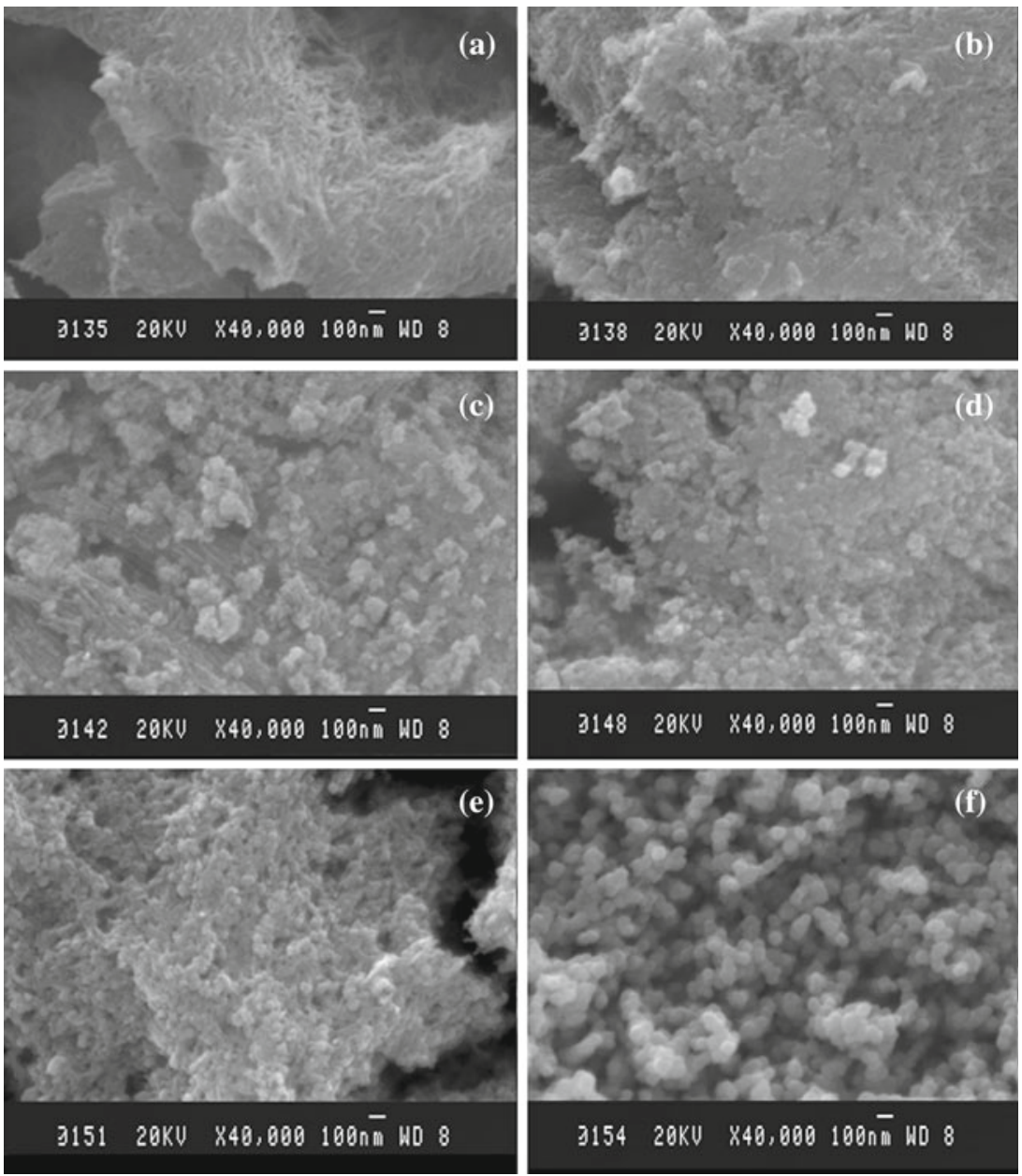

Figure 2. SEM images of electroless nickel deposits formed on anodized aluminium at various deposition times: (a) $20 \mathrm{~s}$, (b) $30 \mathrm{~s}$, (c) $50 \mathrm{~s}$, (d) $90 \mathrm{~s}$, (e) $120 \mathrm{~s}$, (f) $180 \mathrm{~s}$, (g) $300 \mathrm{~s}$, (h) $600 \mathrm{~s}$, (i) $900 \mathrm{~s}$, (j) $1200 \mathrm{~s}$ and (k) $1800 \mathrm{~s}$. 

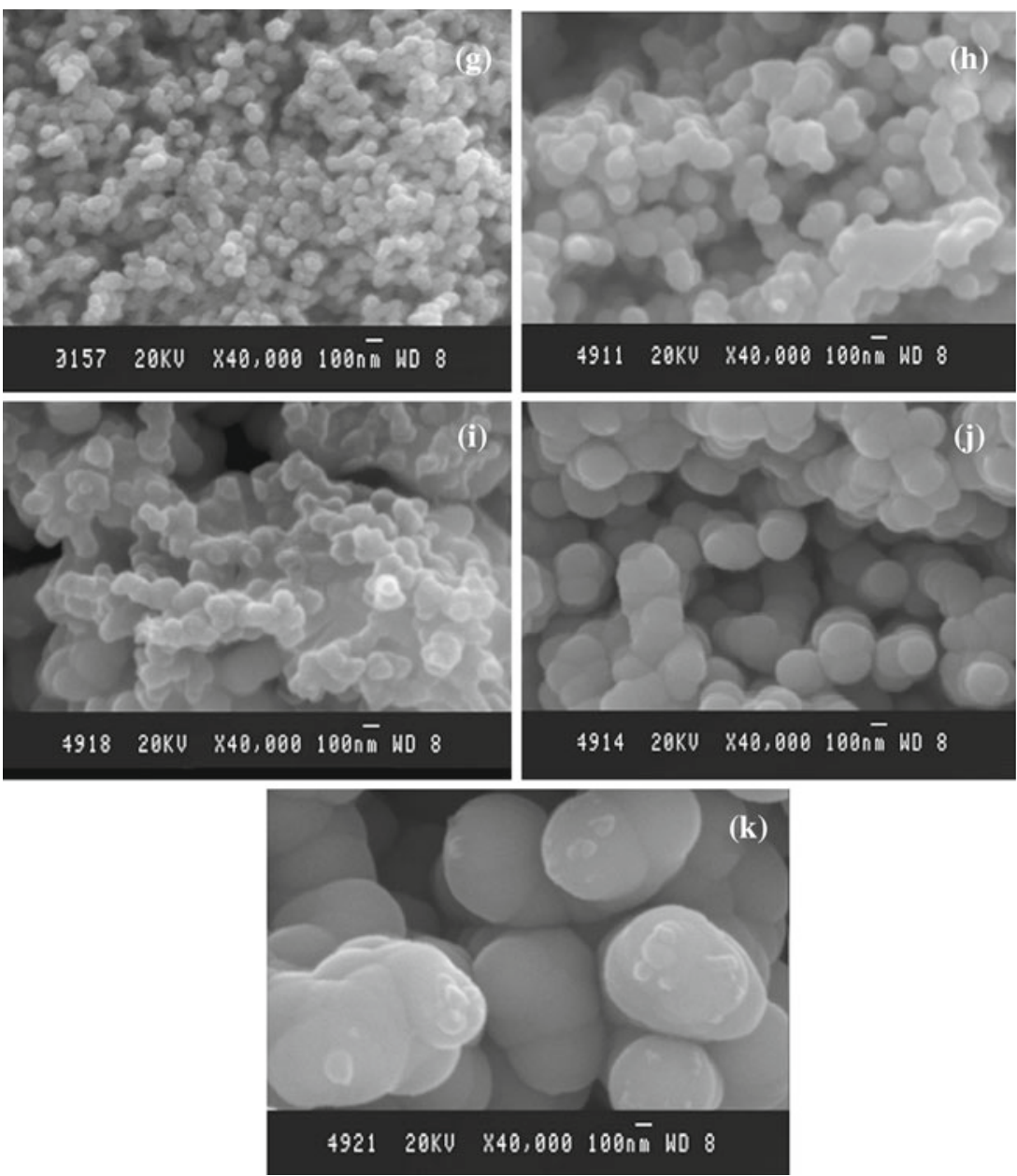

Figure 2. (continued).
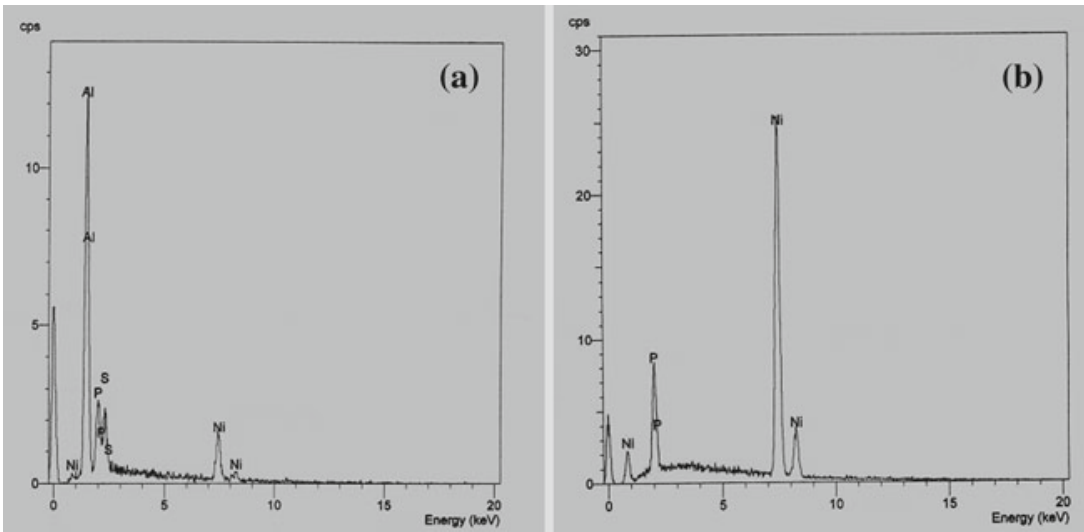

Figure 3. EDAX spectra of electroless Ni-P coatings formed on anodized aluminium: (a) $30 \mathrm{~s}$ and (b) $1800 \mathrm{~s}$.

deposition time decreases the sulphur peak height and finally disappears. Correspondingly, the Ni peak height increases. It is revealed that the coating has higher content of phosphorus along with nickel and lesser amount of sulphur in the initial deposition time. As the deposition time increases, atomic percentage of phosphorus decreases. Similar trend has been reported earlier (Yajima et al 1987).

\subsection{AFM analysis}

Figures $4(\mathrm{a}-\mathrm{c})$ and $5(\mathrm{a}-\mathrm{c})$ show atomic force microscopic (AFM) images of (a) topographical image (2D), (b) threedimensional (3D) image and (c) depth profile analysis of electroless nanocrystalline Ni-P deposits formed in 30 and $1800 \mathrm{~s}$, respectively. It is clearly seen from figure $4(\mathrm{a}, \mathrm{b})$ 
(a)

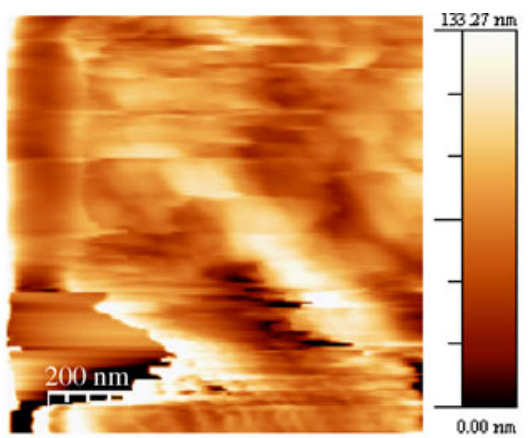

(b)

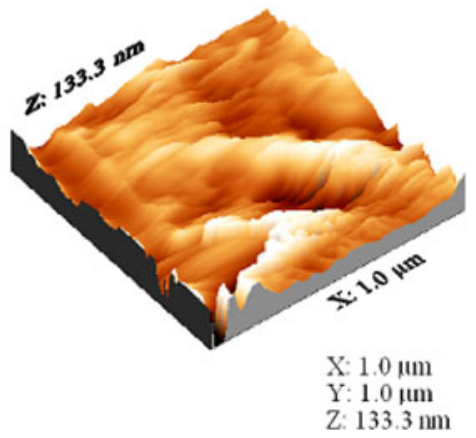

(c)

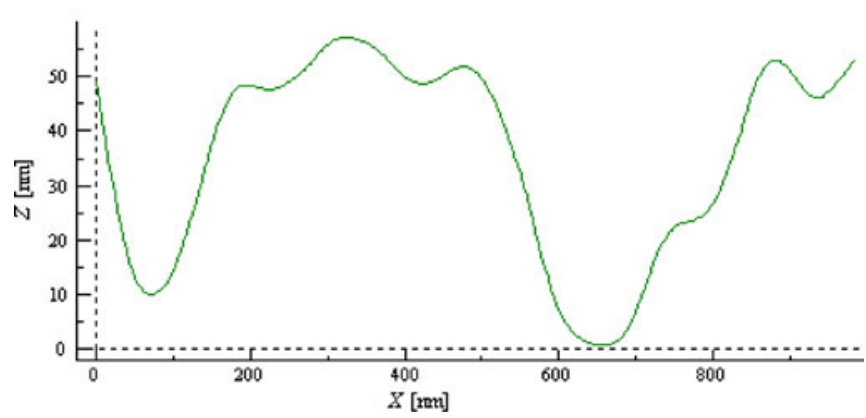

Figure 4. AFM images of as-deposited electroless Ni-P coating formed on anodized aluminium for deposition time of $30 \mathrm{~s}$ : (a) topographic image, (b) 3-dimensional image and (c) depth profile analysis.

that electroless nickel coating formed in $30 \mathrm{~s}$ is composed of uniform layer of Ni-P nanocrystals. AAO surface was completely covered by black nanocrystals of Ni-P. There were no cracks or pits on the surface. Depth profile analysis in horizontal direction (figure 4(c)) shows small number of peaks in the measured surface area of $1 \times 1 \mu \mathrm{m}$. Crystal size is in the range of $10-100 \mathrm{~nm}$.

When electroless nickel deposition time is increased to $1800 \mathrm{~s}$, coating has large number of Ni-P nanocrystals, combined to form almost uniform morphology as shown in figure 5(a, b). In this deposition time, no definite grains are found without any cracks. Figure 5(c) depicts depth profile analysis in the horizontal direction. Smaller peaks are present in the measured area of $1 \times 1 \mu \mathrm{m}$. Crystal size is in the range of $<100 \mathrm{~nm}$. AFM results showed that surface of the coating is nanocrystalline and compact in the as-deposited state for both these deposition times. (a)

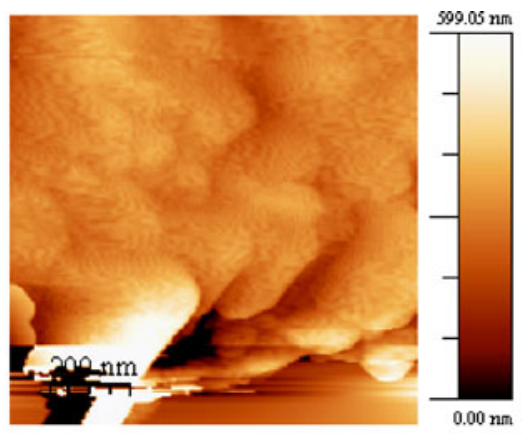

(b)

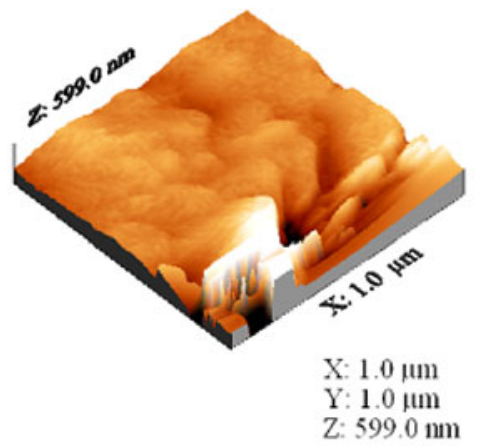

(c)

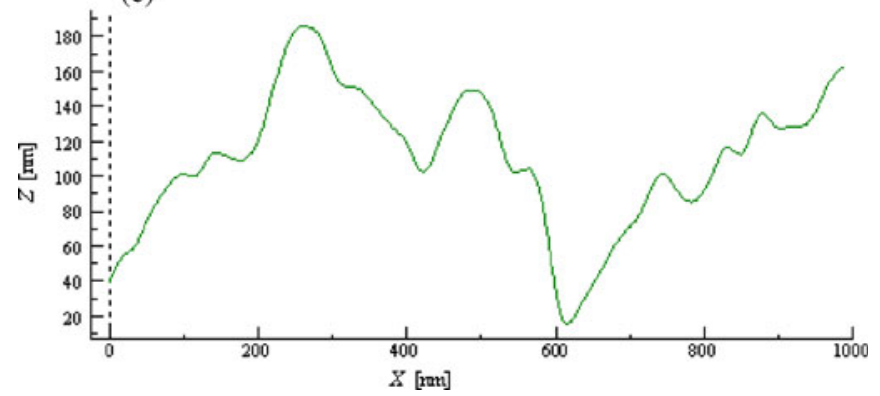

Figure 5. AFM images of as-deposited electroless $\mathrm{Ni}-\mathrm{P}$ coating formed on anodized aluminium for deposition time of $1800 \mathrm{~s}$ : (a) topographic image, (b) 3-dimensional image and (c) depth profile analysis.

Compared to that of anodized aluminium, average surface roughness $\left(R_{\mathrm{a}}\right)$ value is less for the as-deposited coating. It is due to filling of the nanopores by Ni-P on the AAO film during electroless Ni-P deposition process. Roughness value at $30 \mathrm{~s}$ is $58.2 \mathrm{~nm}$ and $1800 \mathrm{~s}$ is $36.3 \mathrm{~nm}$ and the corresponding root mean square (RMS) values are 79.7 and $46.5 \mathrm{~nm}$, respectively. The roughness value reveals that electroless NC-Ni-P coating consists of a large number of nanocrystals in the nanoporous AAO film.

\subsection{XRD analysis}

X-ray diffraction patterns of the as-deposited samples formed at different deposition times from 20 to $1800 \mathrm{~s}$ are given in figure $6(\mathrm{a}-\mathrm{k})$. The as-deposited coating contains nickel and phosphorus peaks. Average crystal size of the $\mathrm{Ni}-\mathrm{P}$ coatings was calculated using Scherrer's equation, 


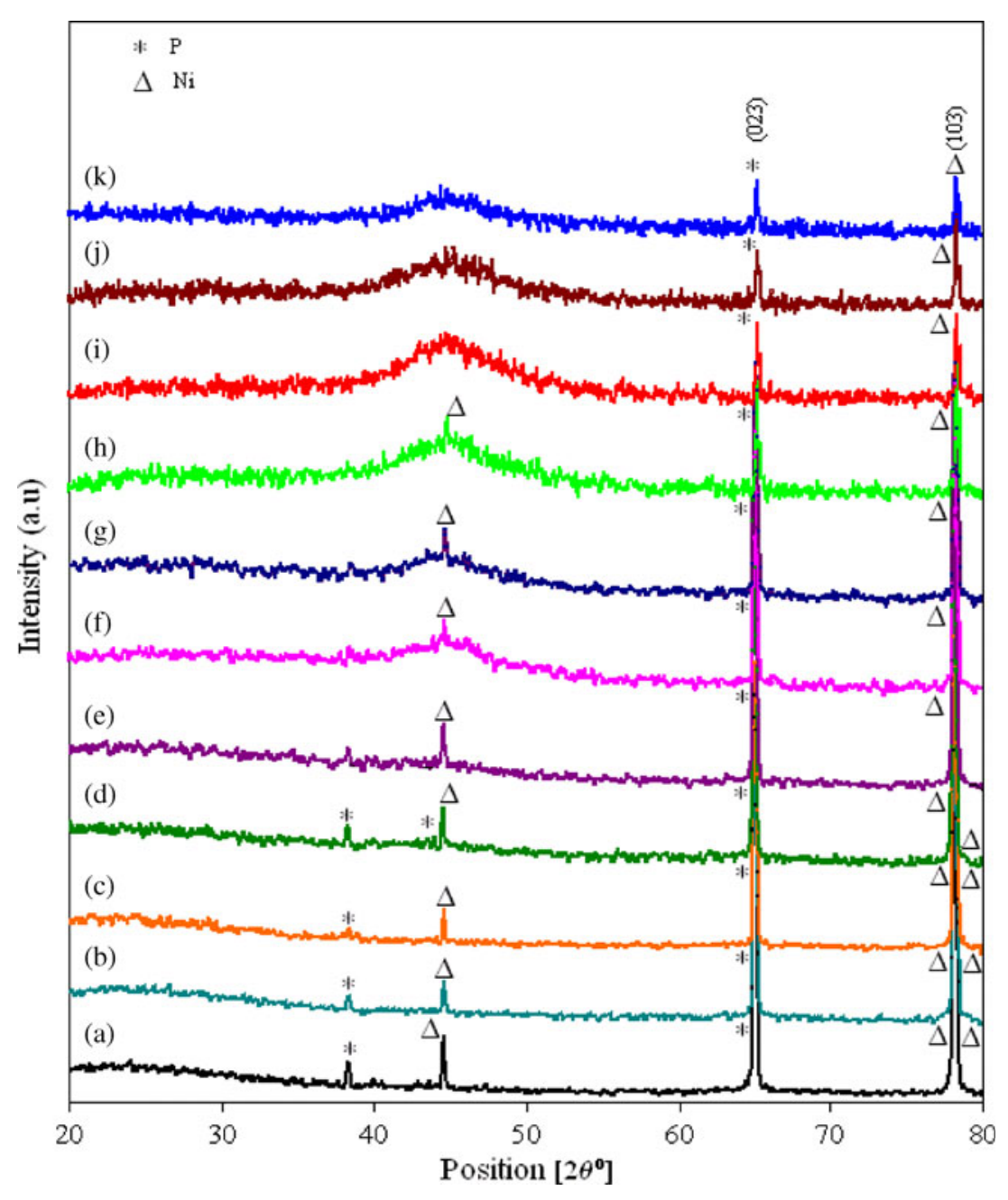

Figure 6. XRD patterns of electroless Ni-P coatings formed on anodized aluminium at various deposition times: (a) $20 \mathrm{~s}$, (b) $30 \mathrm{~s}$, (c) $50 \mathrm{~s}$, (d) $90 \mathrm{~s}$, (e) $120 \mathrm{~s}$, (f) $180 \mathrm{~s}$, (g) $300 \mathrm{~s}$, (h) $600 \mathrm{~s}$, (i) $900 \mathrm{~s}$, (j) $1200 \mathrm{~s}$ and (k) $1800 \mathrm{~s}$.

$D=0.9 \lambda / \beta \cos \theta$ (Birks and Friedman 1946), where $\lambda$ is the wavelength of radiation, $\beta$ is the full width at half maximum (FWHM), $\theta$ is the diffraction angle of the main peak. Joint Committee of Powder Diffraction Standards (JCPDS) database card file index was used to analyse the XRD pattern. Peak positions $(2 \theta), d$-spacing values, plane orientations, structure and crystal size according to the JCPDS file are given in table 1.

Figure 6(a) shows XRD pattern of electroless Ni-P deposit formed at $20 \mathrm{~s}$. It shows $\mathrm{P}\left(\begin{array}{lll}1 & 1 & 8\end{array}\right)$ peak at $38.34^{\circ}$ (JCPDS file no. 75-0577), $\mathrm{Ni}\left(\begin{array}{lll}0 & 1 & 1\end{array}\right)$ peak at $44.58^{\circ}$ (JCPDS file no. 451027), $\mathrm{P}\left(\begin{array}{l}0 \\ 2\end{array}\right)$ ) peak at $64.94^{\circ}$ (JCPDS file no. 65-2491) and

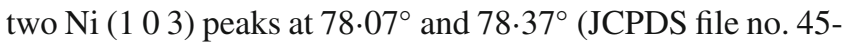
1027). For the deposition time of $30 \mathrm{~s}$ (figure 6(b)), XRD pattern of the coating shows two phosphorus peaks at $38.37^{\circ}$ and $64.98^{\circ}$ with $\left(\begin{array}{lll}1 & 1 & 8\end{array}\right)$ and $\left(\begin{array}{lll}1 & 0 & 3\end{array}\right)$ orientations, respectively and

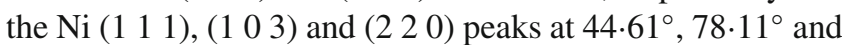
$78.41^{\circ}$ (JCPDS file no. 01-1260, 45-1027, 88-2326), respectively. Figure 6(c) shows XRD pattern of electroless nickel deposit formed at $50 \mathrm{~s}$. It gives the $\mathrm{P}\left(\begin{array}{lll}1 & 1 & 8\end{array}\right)$ peak at $38.38^{\circ}$
(JCPDS file no. 75-0577), Ni (1 111 ) peak at $44.61^{\circ}$ (JCPDS file no. 01-1260), P ( $\left.\begin{array}{lll}0 & 2 & 3\end{array}\right)$ peak at $64.98^{\circ}$ (JCPDS file no. 65-2491), Ni (1 03 ) peak at 78.11 (JCPDS file no. 45-1027) and Ni (2 20 ) peak at $78.40^{\circ}$ (JCPDS file no. 88-2326). Figure 6(d) depicts XRD pattern of electroless nickel deposit formed at $90 \mathrm{~s}$. It gives three phosphorus peaks at $38.27^{\circ}$, $43.55^{\circ}$ and $64.91^{\circ}$ corresponding to $\left(\begin{array}{lll}1 & 1 & 8\end{array}\right),\left(\begin{array}{lll}1 & 3 & 1\end{array}\right)$ and $\left(\begin{array}{lll}0 & 2 & 3\end{array}\right)$ orientations, respectively and three nickel peaks at $44.53^{\circ}, 78.04^{\circ}$ and $78.33^{\circ}$ corresponding to $\left(\begin{array}{lll}1 & 1 & 1\end{array}\right),\left(\begin{array}{lll}1 & 0 & 3\end{array}\right)$ and (2 220$)$ orientations, respectively. Figure 6(e) shows XRD pattern of electroless nickel deposit formed at $120 \mathrm{~s}$. It gives four peaks at $38.23^{\circ}, 44.58^{\circ}, 64.94^{\circ}$ and $78.08^{\circ}$ corresponding to $\mathrm{P}\left(\begin{array}{lll}1 & 1 & 8\end{array}\right), \mathrm{Ni}\left(\begin{array}{lll}0 & 1 & 1\end{array}\right), \mathrm{P}\left(\begin{array}{lll}0 & 2 & 3\end{array}\right)$ and $\mathrm{Ni}\left(\begin{array}{lll}1 & 0 & 3\end{array}\right)$, respectively. Figure 6(f-h) shows electroless Ni-P deposit formed at 180,300 and $600 \mathrm{~s}$, respectively. The coating formed at $180 \mathrm{~s}$ gives three peaks at $44.53^{\circ}, 65^{\circ}$ and $78.13^{\circ}$ and the coating formed at $300 \mathrm{~s}$ gives the same peaks at $44.70^{\circ}, 65.03^{\circ}$ and $78.16^{\circ}$ and that formed at $600 \mathrm{~s}$ gives the same peaks at $44.93^{\circ}, 65.15^{\circ}$ and $78.28^{\circ}$ corresponding to the same plane orientations $\mathrm{Ni}\left(\begin{array}{lll}1 & 1 & 1\end{array}\right), \mathrm{P}\left(\begin{array}{lll}0 & 2 & 3\end{array}\right)$ and $\mathrm{Ni}\left(\begin{array}{lll}1 & 0 & 3\end{array}\right)$, respectively. 
Table 1. XRD results of electroless nanocrystalline Ni-P coatings formed on anodized aluminium at various deposition times.

\begin{tabular}{|c|c|c|c|c|c|c|c|c|c|c|c|}
\hline \multirow{2}{*}{$\begin{array}{l}\text { Deposition } \\
\text { time }(\mathrm{s})\end{array}$} & \multirow{2}{*}{$\begin{array}{l}\text { Position } \\
\left(2 \theta^{\circ}\right)\end{array}$} & \multirow{2}{*}{$\begin{array}{c}\text { ' } d \text { ' } \\
\text { observed }\end{array}$} & \multirow{2}{*}{$\begin{array}{c}\text { ' } d \text { ' } \\
\text { standard }\end{array}$} & \multirow{2}{*}{$\begin{array}{l}\text { Indexing } \\
\text { plane }\end{array}$} & \multirow{2}{*}{$\begin{array}{l}\text { JCPDS } \\
\text { file no. }\end{array}$} & \multicolumn{3}{|c|}{ Lattice parameters } & \multirow[b]{2}{*}{ Structure } & \multirow{2}{*}{$\begin{array}{c}\text { Particle } \\
\text { size }(n m)\end{array}$} & \multirow{2}{*}{$\begin{array}{l}\text { Average particle } \\
\quad \text { size }(\mathrm{nm})\end{array}$} \\
\hline & & & & & & $\mathrm{a}$ & $\mathrm{b}$ & $\mathrm{c}$ & & & \\
\hline \multirow[t]{5}{*}{20} & $38 \cdot 34$ & $2 \cdot 347$ & $2 \cdot 334$ & $\mathrm{P}(118)$ & $75-0577$ & $9 \cdot 21$ & \multirow[t]{2}{*}{$9 \cdot 15$} & $22 \cdot 6$ & Monoclinic & $42 \cdot 75$ & \multirow[t]{5}{*}{$54 \cdot 34$} \\
\hline & $44 \cdot 58$ & $2 \cdot 032$ & $2 \cdot 033$ & $\mathrm{Ni}(011)$ & $45-1027$ & $2 \cdot 6515(4)$ & & $4 \cdot 343(3)$ & Hexagonal & $43 \cdot 65$ & \\
\hline & 64.94 & 1.435 & 1.409 & $\mathrm{P}(023)$ & $65-2491$ & $3 \cdot 316$ & \multirow[t]{3}{*}{$10 \cdot 52$} & $4 \cdot 389$ & Orthorhombic & $47 \cdot 87$ & \\
\hline & $78 \cdot 07$ & $1 \cdot 223$ & $1 \cdot 223$ & $\mathrm{Ni}(103)$ & $45-1027$ & $2 \cdot 6515(4)$ & & $4 \cdot 343(3)$ & Hexagonal & 51.99 & \\
\hline & $78 \cdot 37$ & $1 \cdot 222$ & $1 \cdot 223$ & Ni(103) & $45-1027$ & $2 \cdot 6515(4)$ & & $4 \cdot 343(3)$ & Hexagonal & $85 \cdot 45$ & \\
\hline \multirow[t]{5}{*}{30} & $38 \cdot 37$ & $2 \cdot 345$ & $2 \cdot 3341$ & $\mathrm{P}(118)$ & $75-0577$ & $9 \cdot 21$ & \multirow[t]{5}{*}{$9 \cdot 15$} & $22 \cdot 6$ & Monoclinic & $28 \cdot 50$ & \multirow[t]{5}{*}{$48 \cdot 31$} \\
\hline & $44 \cdot 61$ & $2 \cdot 031$ & $2 \cdot 03$ & $\mathrm{Ni}(111)$ & $01-1260$ & $3 \cdot 5175$ & & & Cubic & $43 \cdot 65$ & \\
\hline & 64.98 & 1.435 & 1.409 & $\mathrm{P}(023)$ & $65-2491$ & $3 \cdot 316$ & & $4 \cdot 389$ & Orthorhombic & 31.92 & \\
\hline & $78 \cdot 11$ & $1 \cdot 223$ & $1 \cdot 223$ & $\mathrm{Ni}(103)$ & $45-1027$ & $2 \cdot 6515(4)$ & & $4 \cdot 343(3)$ & Hexagonal & $52 \cdot 01$ & \\
\hline & $78 \cdot 41$ & $1 \cdot 218$ & $1 \cdot 219$ & $\mathrm{Ni}(220)$ & $88-2326$ & $3 \cdot 45$ & & & Cubic & $85 \cdot 48$ & \\
\hline \multirow[t]{5}{*}{50} & $38 \cdot 38$ & $2 \cdot 344$ & $2 \cdot 334$ & $\mathrm{P}(118)$ & $75-0577$ & $9 \cdot 21$ & \multirow[t]{5}{*}{$9 \cdot 15$} & $22 \cdot 6$ & Monoclinic & $14 \cdot 25$ & \multirow[t]{5}{*}{$48 \cdot 65$} \\
\hline & $44 \cdot 61$ & $2 \cdot 030$ & $2 \cdot 03$ & $\mathrm{Ni}(111)$ & $01-1260$ & $3 \cdot 5175$ & & & Cubic & $43 \cdot 65$ & \\
\hline & 64.98 & 1.435 & 1.409 & $\mathrm{P}(023)$ & $65-2491$ & $3 \cdot 316$ & & $4 \cdot 389$ & Orthorhombic & $47 \cdot 88$ & \\
\hline & $78 \cdot 11$ & $1 \cdot 223$ & $1 \cdot 223$ & Ni(103) & $45-1027$ & $2 \cdot 6515(4)$ & & $4 \cdot 343(3)$ & Hexagonal & $52 \cdot 01$ & \\
\hline & $78 \cdot 40$ & $1 \cdot 218$ & $1 \cdot 219$ & $\mathrm{Ni}(220)$ & $88-2326$ & $3 \cdot 45$ & & & Cubic & $85 \cdot 47$ & \\
\hline \multirow[t]{6}{*}{90} & $38 \cdot 27$ & $2 \cdot 351$ & $2 \cdot 334$ & $\mathrm{P}(118)$ & $75-0577$ & $9 \cdot 21$ & $9 \cdot 15$ & 22.6 & Monoclinic & $28 \cdot 5$ & $48 \cdot 33$ \\
\hline & $43 \cdot 55$ & 2.078 & $2 \cdot 071$ & $\mathrm{P}(131)$ & 76-1965 & $3 \cdot 3114(6)$ & \multirow[t]{2}{*}{$10 \cdot 189$} & $4 \cdot 254(1)$ & Orthorhombic & $24 \cdot 85$ & \\
\hline & $44 \cdot 53$ & $2 \cdot 034$ & $2 \cdot 034$ & $\mathrm{Ni}(111)$ & $65-2865$ & $3 \cdot 524$ & & & Cubic & $43 \cdot 64$ & \\
\hline & 64.91 & 1.436 & 1.409 & $\mathrm{P}(023)$ & $65-2491$ & $3 \cdot 316$ & $10 \cdot 52$ & $4 \cdot 389$ & Orthorhombic & $38 \cdot 29$ & \\
\hline & $78 \cdot 04$ & $1 \cdot 224$ & $1 \cdot 223$ & $\mathrm{Ni}(103)$ & $45-1027$ & $2 \cdot 6515(4)$ & & $4 \cdot 343(3)$ & Hexagonal & $69 \cdot 31$ & \\
\hline & $78 \cdot 33$ & $1 \cdot 219$ & $1 \cdot 219$ & $\mathrm{Ni}(220)$ & $88-2326$ & 3.45 & & & Cubic & $85 \cdot 43$ & \\
\hline 120 & $38 \cdot 23$ & $2 \cdot 3523$ & $2 \cdot 3341$ & $\mathrm{P}(118)$ & $75-0577$ & $9 \cdot 21$ & $9 \cdot 15$ & $22 \cdot 6$ & Monoclinic & $14 \cdot 24$ & $36 \cdot 67$ \\
\hline & $44 \cdot 58$ & $2 \cdot 0324$ & $2 \cdot 0334$ & $\mathrm{Ni}(011)$ & $45-1027$ & $2 \cdot 6515(4)$ & & $4 \cdot 343(3)$ & Hexagonal & $43 \cdot 67$ & \\
\hline & 64.94 & 1.4358 & 1.4095 & $\mathrm{P}(023)$ & $65-2491$ & $3 \cdot 316$ & $10 \cdot 52$ & $4 \cdot 389$ & Orthorhombic & $31 \cdot 91$ & \\
\hline & $78 \cdot 08$ & $1 \cdot 2228$ & $1 \cdot 2239$ & $\mathrm{Ni}(103)$ & $45-1027$ & $2 \cdot 6515(4)$ & & & Hexagonal & $56 \cdot 85$ & \\
\hline 180 & $44 \cdot 53$ & $2 \cdot 0343$ & $2 \cdot 0344$ & $\mathrm{Ni}(111)$ & $87-0712$ & $3 \cdot 5238$ & & & Hexagonal & 5.45 & $33 \cdot 54$ \\
\hline & $65 \cdot 00$ & 1.4347 & 1.4095 & $\mathrm{P}(023)$ & $65-2491$ & $3 \cdot 316$ & $10 \cdot 52$ & $4 \cdot 389$ & Orthorhombic & $38 \cdot 31$ & \\
\hline & $78 \cdot 13$ & $1 \cdot 2218$ & $1 \cdot 2239$ & $\mathrm{Ni}(103)$ & $45-1027$ & $2 \cdot 6515(4)$ & & $4 \cdot 343(3)$ & Hexagonal & $56 \cdot 87$ & \\
\hline 300 & $44 \cdot 70$ & $2 \cdot 0273$ & $2 \cdot 0297$ & $\mathrm{Ni}(111)$ & 70-0989 & $3 \cdot 5157$ & & & Cubic & $58 \cdot 22$ & $44 \cdot 27$ \\
\hline & $65 \cdot 03$ & 1.4341 & 1.4095 & $\mathrm{P}(023)$ & $65-2491$ & $3 \cdot 316$ & $10 \cdot 52$ & $4 \cdot 389$ & Orthorhombic & 31.93 & \\
\hline & $78 \cdot 16$ & $1 \cdot 2218$ & $1 \cdot 2239$ & $\mathrm{Ni}(103)$ & $45-1027$ & $2 \cdot 6515(4)$ & & $4 \cdot 343(3)$ & Hexagonal & $42 \cdot 66$ & \\
\hline 600 & 44.93 & $2 \cdot 0154$ & $2 \cdot 0344$ & $\mathrm{Ni}(111)$ & $01-1266$ & $3 \cdot 499$ & & & Cubic & 2.744 & $48 \cdot 7$ \\
\hline & $65 \cdot 15$ & 1.4305 & 1.4095 & $\mathrm{P}(023)$ & $65-2491$ & $3 \cdot 316$ & $10 \cdot 52$ & $4 \cdot 389$ & Orthorhombic & $76 \cdot 81$ & \\
\hline & $78 \cdot 28$ & $1 \cdot 220$ & $1 \cdot 223$ & $\mathrm{Ni}(103)$ & $45-1027$ & $2 \cdot 6515(4)$ & & $4 \cdot 343(3)$ & Hexagonal & $66 \cdot 54$ & \\
\hline 900 & $65 \cdot 17$ & 1.430 & 1.409 & $\mathrm{P}(023)$ & $65-2491$ & $3 \cdot 316$ & $10 \cdot 52$ & $4 \cdot 389$ & Orthorhombic & $42 \cdot 91$ & $50 \cdot 64$ \\
\hline & $78 \cdot 29$ & $1 \cdot 220$ & $1 \cdot 223$ & $\mathrm{Ni}(103)$ & $45-1027$ & $2 \cdot 6515(4)$ & & $4 \cdot 343(3)$ & Hexagonal & $58 \cdot 36$ & \\
\hline 1200 & $65 \cdot 16$ & 1.430 & 1.409 & $\mathrm{P}(023)$ & $65-2491$ & $3 \cdot 316$ & $10 \cdot 52$ & $4 \cdot 389$ & Orthorhombic & $39 \cdot 05$ & $54 \cdot 79$ \\
\hline & $78 \cdot 27$ & $1 \cdot 220$ & $1 \cdot 223$ & $\mathrm{Ni}(103)$ & $45-1027$ & $2 \cdot 6515(4)$ & & $4 \cdot 343(3)$ & Hexagonal & $70 \cdot 52$ & \\
\hline 1800 & $65 \cdot 12$ & 1.431 & 1.409 & $\mathrm{P}(023)$ & $65-2491$ & $3 \cdot 316$ & $10 \cdot 52$ & $4 \cdot 389$ & Orthorhombic & $69 \cdot 29$ & $72 \cdot 28$ \\
\hline & $78 \cdot 24$ & $1 \cdot 220$ & $1 \cdot 223$ & $\mathrm{Ni}(103)$ & $45-1027$ & $2 \cdot 6515(4)$ & & $4 \cdot 343(3)$ & Hexagonal & $75 \cdot 27$ & \\
\hline
\end{tabular}

By comparing the XRD patterns, it is found that as the deposition time increases, the phosphorus peak occurring at around $2 \theta=38^{\circ}$ gradually disappears, which indicates that the Ni-P coating occurs on the surface of the anodized aluminium sample with the same plane orientation, P $\left(\begin{array}{lll}1 & 1 & 8\end{array}\right)$. The sharp peak appearing at around $44^{\circ}$ corresponds to the $\left(\begin{array}{lll}1 & 1 & 1\end{array}\right)$ diffraction of cubic nanocrystalline nickel. On increasing the deposition time (figure $6(\mathrm{f}-\mathrm{h})$ ), mixture of amorphous/nanocrystalline peaks is visible up to $600 \mathrm{~s}$. On increasing deposition time, amorphous with nanocrystalline peak is converted into the fully amorphous Ni-P band with low intensity in the range of $40-55^{\circ}$ due to the changes in the close packing arrangement of $f c c \mathrm{Ni}$. El Mahallawy et al (2008) observed that the broad peak might belong to only $\mathrm{Ni}$ and $\mathrm{P}$ may not be visible because it is amorphous. They noticed that a broad peak with a width larger than $10^{\circ}$ occurs as a result of the superposition of $\mathrm{Ni}$ and $\mathrm{Ni}-\mathrm{P}$ alloy peaks at $48-62^{\circ}$ which corresponds to an amorphous material. In another study (Sharma et al 1998), it was mentioned that the as-deposited coating is amorphous, containing Ni and $\mathrm{P}$ separately. Plane orientation changes with time towards more compactness of the deposited $\mathrm{Ni}-\mathrm{P}$ coatings 


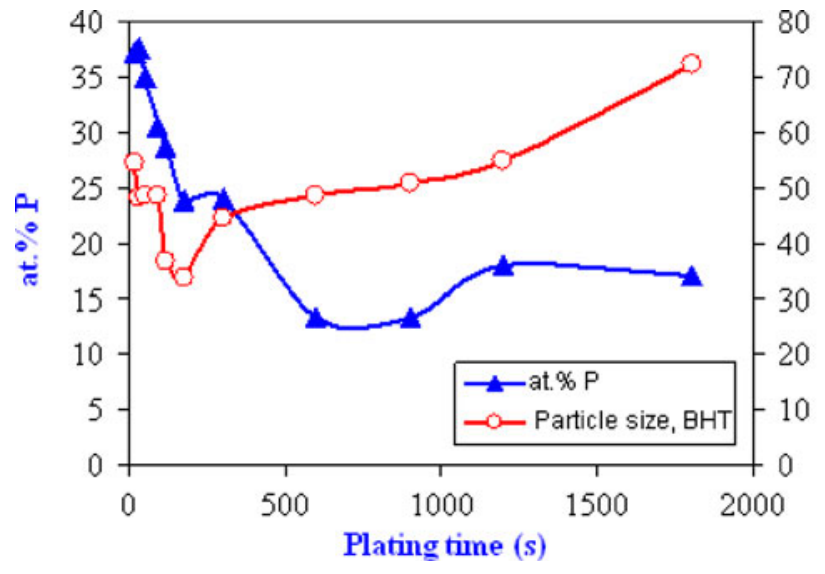

Figure 7. Effect of plating time on atomic percent of phosphorus and particle size.

and the $\mathrm{P}\left(\begin{array}{lll}0 & 2 & 3\end{array}\right), \mathrm{Ni}\left(\begin{array}{lll}1 & 0 & 3\end{array}\right)$ peaks were observed at around $65^{\circ}$ and $78^{\circ}$ as shown in figure 6(i-k) (Lo et al 1994; Zeller and Salvati 1994; Saito et al 1999). It confirms that when the deposition time is $1800 \mathrm{~s}$, the coatings have high phosphorous content, which is in good agreement with EDAX analysis.

Figure 7 shows effect of plating time on atomic percentage of phosphorus and particle size of the Ni-P coatings in the as-deposited condition. As the deposition time increases from 20 to $180 \mathrm{~s}$, average crystal size decreases from 54 to $33 \mathrm{~nm}$. After $180 \mathrm{~s}$, crystal size gradually increases. Average crystal size is $72 \mathrm{~nm}$ for plating time of $1800 \mathrm{~s}$. However, by increasing deposition time, at.\% of phosphorus decreases to some extent and after that, it increases in a parabolic manner. During the initial stages of electroless deposition, both oxidation of reducing agent and reduction of metal ion taking place on a catalytic surface lead to high rate of deposition. Other side reactions are hydrogen evolution and deposition of phosphorus along with nickel. This co-deposition of phosphorous, a non-catalytic material, reduces the rate of deposition continuously. However, P content in the deposit also reduces up to about $180 \mathrm{~s}$ and after that, $\mathrm{pH}$ of the electrolyte adjacent to the reaction centre reduces slowly due to the formation of $\mathrm{H}^{+}$ions. The following reactions favour the deposition of nickel and phosphorus from the hypophosphite bath (Ashassi-Sorkhabi et al 2005).

$$
\mathrm{Ni}^{2+}+2 \mathrm{H}_{2} \mathrm{PO}_{2}^{-}+2 \mathrm{H}_{2} \mathrm{O} \rightarrow \mathrm{Ni}+2 \mathrm{H}_{2} \mathrm{PO}_{3}^{-}+\mathrm{H}_{2}+2 \mathrm{H}^{+},
$$

$$
2 \mathrm{H}_{2} \mathrm{PO}_{2}^{-}+\mathrm{H}^{+} \rightarrow \mathrm{H}_{2} \mathrm{PO}_{3}^{-}+\mathrm{P}+\mathrm{H}+\mathrm{H}_{2} \mathrm{O} .
$$

Such formation of $\mathrm{H}^{+}$favours further $\mathrm{P}$ deposition due to the lower $\mathrm{pH}$ in the solution than bulk of the electrolyte (Iranipour et al 2010; El Mahallawy et al 2008). Crystal size variation observed in the plating process, which implies that the crystal growth of the deposited Ni-P is a diffusion controlled process (Guo et al 2003).

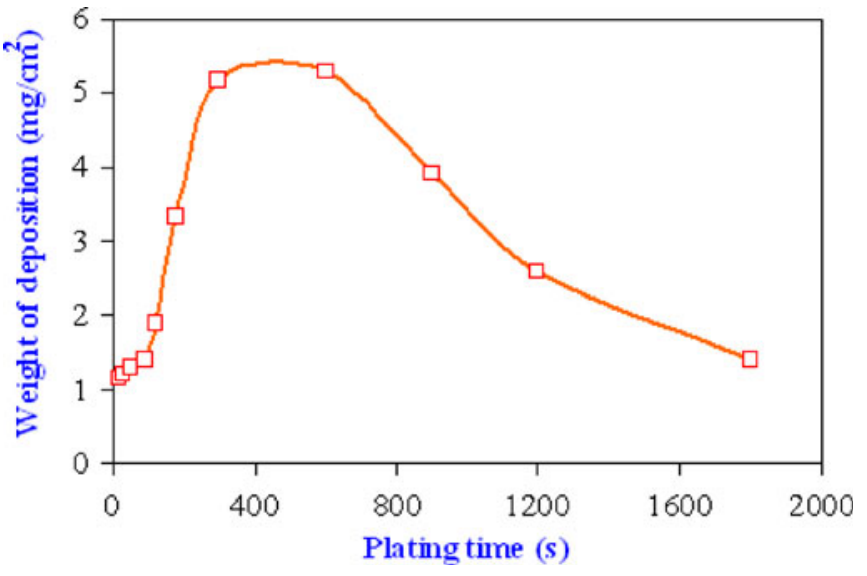

Figure 8. Effect of plating time on weight of deposition.

Figure 8 shows effect of coating time on weight of the $\mathrm{Ni}-\mathrm{P}$ deposit formed at optimum conditions. As deposition time increases from 20 to $1800 \mathrm{~s}$, weight of the deposit increases up to $600 \mathrm{~s}$ and then decreases. Maximum weight of deposit is obtained at the deposition of $600 \mathrm{~s}$. The deposit weight gain curves are nonlinear as reported earlier (Sharma et al 1998). Weight of the deposit in the early stage is high due to the presence of a large number of pores in the anodized aluminium and higher specific area. The coating is mainly nanoporous $\mathrm{Al}_{2} \mathrm{O}_{3}$, which consequently provides more nucleus sites for the nucleation of crystals. This may facilitate the formation of nanocrystalline deposits.

\subsection{UV reflectance study}

Plating time is found to play an important role in the nature and colour of electroless nanocrystalline nickel deposit. As the deposition time increased from 20 to $1800 \mathrm{~s}$, the electroless bath produced brown, dark brown, black, greyish black, grey, light grey with metallic lustre and finally nickel finish on anodized aluminium. This may be due to the gradual filling of nickel deposits in the pores of the anodized aluminium (John et al 1983; Srinivasan et al 1984; Brown et al 2002; Cui et al 2006).

UV reflectance of the black to bright nanocrystalline coating on AAO film produced at $20 \mathrm{~s}$ is $16.92 \%, 50 \mathrm{~s}$ is $10.76 \%$, $300 \mathrm{~s}$ is $11.25 \%, 600 \mathrm{~s}$ is $14.79 \%$ and $1200 \mathrm{~s}$ is $14.86 \%$. It can be seen that as the deposition time increases, reflectance of the UV light decreases as the black Ni coating absorbs more amount of UV light. Further deposition of nanoparticles of electroless Ni-P at the pores further increases the absorbance of light. About $89 \%$ absorption leads to black colour.

\section{Conclusions}

Electroless nickel deposits on anodic aluminium oxide film formed in $30 \mathrm{~s}$ is composed of uniform layer of black Ni-P nanocrystals. Larger number of NC-Ni-P crystals combined to form almost uniform morphology at $1800 \mathrm{~s}$ plating time. 
Atomic percentage of phosphorus in the Ni-P coating with different plating times follows parabolic manner. As the deposition time increases, reflectance value of $\mathrm{NC}-\mathrm{Ni}-\mathrm{P}$ in the visible region decreases and sharp NC-Ni-P is transformed into amorphous peak indicating crystal growth formation on the surface of the anodized aluminium sample with the same plane orientation.

\section{Acknowledgement}

The authors gratefully acknowledge Prof. P Manisankar, Alagappa University, Karaikudi, for his generous help in characterization studies.

\section{References}

Apachitei I, Duszczyk J, Katgerman L and Overkamp P J B 1998 Scr. Mater. 381347

Ashassi-Sorkhabi H, Mirmohseni A, Harrafi H 2005 Electrochim. Acta $\mathbf{5 0} 5526$

Baskaran I, Sankara Narayanan T S N and Stephen A 2006 Mater. Chem. Phys. 99117

Birks L S and Friedman H 1946 J. Appl. Phys. 17687

Brenner A and Riddell G E 1946 J. Res. Nat. Bur. Stand. 3731

Brown R J C, Brewer P J and Milton M J T 2002 J. Mater. Chem. 122749

Chow G M and Ovid'ko I 2000 Nano-structured films and coatings, North Atlantic Treaty Organization (NATO) Science Series, 3. High Technology (ed.) T Tsakalakos (Dordrecht: Kluwer Academic Publishers) vol. 78

Cui G, Li N, Li D, Zheng J and Wu Q 2006 Surf. Coat. Technol. 200 6808

El Mahallawy N, Bakkar A, Shoeib M, Palkowski H and Neubert V 2008 Surf. Coat. Technol. 2025151

Fundo A M and Abrantes L M 2007 J. Electroanal. Chem. 60063

Goldenstein A W, Rostoker W, Schossberger F and Gutzeit G 1957 J. Electrochem. Soc. 104104
Goueffon Y, Arurault L, Mabru C, Tonon C and Guigue P 2009 J. Mater. Process. Technol. 2095145

Guo Z, Keong K G and Sha W 2003 J. Alloys Compd. 358112

Huang Y S and Cui F Z 2007 Surf. Coat. Technol. 2015416

Hur K H, Jeong J H and Lee D N 1990 J. Mater. Sci. 252573

Iranipour N, Azari Khosroshahi R and Parvini Ahmadi N 2010 Surf. Coat. Technol. 2052281

John S, Shanmugan N V, Srinivasan K N, Selvam M and Shenoi B A 1983 Surf. Coat. Technol. 20331

Keong K G, Sha W and Malinov S 2002 J. Alloys Compd. 334192 Kumar P S and Nair P K 1994 J. Mater. Sci. Lett. 13671

Li L B, An M Z and Wu G H 2005 Mater. Chem. Phys. 94159

Liu Z and Gao W 2006 Surf. Coat. Technol. 2003553

Lo P H, Tsai W T, Lee J T and Hung M P 1994 Surf. Coat. Technol. 6727

Lu G and Zangari G 2002 Electrochim. Acta 472969

Mallory G O and Hajdu J B 1990 Electroless plating (Norwich, New York: American Electroplaters and Surface Finishing Society)

Martyak N M and Drake K 2000 J. Alloys Compd. 31230

Masuda H and Fukuda K 1995 Science 2681466

Meyer M A, Mishra A and Benson D 2006 J. Prog. Mater. Sci. 51 427

Parker K 1992 Plat. Surf. Finish. 7931

Saito T, Sato E, Matsuoka M and Iwakura C 1999 Plat. Surf. Finish. 223

Sevugan K, Selvam M, Srinivasan K N, Vasudevan T and Manisankar P 1993 Plat. Surf. Finish. 8056

Shacham-Diamad Y and Sverdlov Y 2000 Microelectron. Eng. 50 525

Sharma A K, Suresh M R, Bhojraj H, Narayanamurthy H and Sahu S P 1998 Met. Finish. 310

Srinivasan K N, Shanmugan N V, Selvam M, John S and Shenoi B A 1984 Energy Convers. Manage. 24255

Tyagi S V S, Tandon V K and Ray S 1985 Metallkde Z. 76492

Wang X C, Cai W B, Wang W J, Liu H T and Yu Z Z 2003 Surf. Coat. Technol. 168300

Yajima S, Matsashita S, Togawa Y and Kanbe T 1987 Met. Finish. 153

Zeller R L and Salvati L 1994 Corros. Sci. 6457

Zhao H, Huang Z and Cui J 2007 Surf. Coat. Technol. 202133 